\title{
Sir Herbert Seddon (1903-1977) and his classification scheme for peripheral nerve injury
}

\author{
Yasemin Kaya • Levent Sarikcioglu
}

Received: 31 July 2014 / Accepted: 12 September 2014 / Published online: 1 October 2014

(C) Springer-Verlag Berlin Heidelberg 2014

\begin{abstract}
Sir Herbert Seddon was a visionary neuroscientist and surgeon. Internationally, he is best known for his classification of the peripheral nerve injury, now known as Seddon's classification. The authors reviewed his life with a special emphasis on his legacy to neuroscience.
\end{abstract}

Keywords Sir Herbert Seddon · Neurapraxia $\cdot$ Axonotmesis · Neurotmesis $\cdot$ Peripheral nerve injury

Sir Herbert Seddon was a visionary neuroscientist and surgeon. Internationally, he is best known for his classification scheme for peripheral nerve injury, now known as Seddon's classification.

\section{His life}

Sir Herbert Seddon was born in 1903 in Derby, England. He was educated successively in William Hulme's Grammar School, Manchester, and at St. Bartholomew's Hospital Medical College in London University, graduating from the latter in 1928 with the gold medal. In 1930, he went to Ann Arbor, Michigan, as an instructor in surgery. In 1940, at 37 years of age, he was appointed as the first Nuffield Professor of orthopaedic surgery in Oxford University. He spent the war years at Oxford and established a peripheral nerve injury unit to deal with the large number of military casualties [13]. In 1948, he was appointed resident surgeon in the Royal National Orthopaedic Hospital. During his service in the Royal National

Y. Kaya $\cdot$ L. Sarikcioglu $(\bowtie)$

Department of Anatomy, Akdeniz University Faculty of Medicine, 07070 Antalya, Turkey

e-mail: levent@akdeniz.edu.tr
Orthopaedic Hospital, he obtained a unique experience in the treatment of spinal tuberculosis and poliomyelitis, both of which remained of interest to him throughout his life. He also advised many developing countries on how to manage these diseases, which is still overwhelmingly common in many of them. He also studied on nerve repair and grafting $[10,11]$, thereby the standards for all modern nerve repair and grafting procedures come from his work [15]. He was elected president of the British Orthopaedic Association in 1960 and served in that position for 2 years. He was honoured by a knighthood conferred in 1964 . He received an honorary F.A.C.S. and honorary degrees from Grenoble, Malta and Glasgow. He retired in 1967 but he continued to his research activities and writing $[4,13]$. He died on December 21, 1977, at 74 years of age.

His masterly book, Surgical Disorders of the Peripheral Nerves, which is the most important treatise on the subject, was first published in 1971 [12]. This book was revised and updated after his death. He gained worldwide reputation as a neuroscientist mainly through his monumental works on surgical disorders of the peripheral nerves and the classification of nerve injury.

\section{His legacy to science}

Peripheral nerve trauma may induce a broad spectrum of clinical symptoms, ranging from slight paraesthesia and pain to weakness or paralysis of muscle [8]. Therefore, anatomy of the peripheral nerve is crucial to understand the pathophysiologic concepts needed for the management of patients with peripheral nerve trauma $[1,3,6]$. To understand and manage the peripheral nerve injury, two predominant schemes were proposed: that of Seddon and that of Sunderland [7]. 


\section{Seddon's classification scheme for peripheral nerve injury}

His studies as a surgeon dealing with military casualties suffered from various traumatic lesions of the peripheral nervous system were revealed a classification of nerve injury. Seddon's own personal and clinical observations during World War II undoubtedly contributed more to our knowledge on peripheral nerve repair [13]. Seddon described three types of nerve injury-neurapraxia, axonotmesis and neurotmesis - based upon the severity of tissue injury, prognosis and time for recovery (Figs. 1 and 2) [9]. These terms had also been coined by Henry Cohen, first Baron Cohen of Birkenhead. Seddon adopted these terms to describe the levels of injury [7].

Under this classification, Neurapraxia ("praxis" means "to do, to perform") is the mildest type and refers to a block to conduction of nerve impulses but without disruption of the axon or perineurium [15]. Nerve fibres are unable to conduct an action potential despite axonal continuity and virtually complete return of sensation or function. Since there is no axonal degeneration, conduction block recover within hours, days, weeks or up to a few months [7].

Axonotmesis ("tmesis" means "to cut") refers to loss of axonal continuity without associated disruption of the fascicular connective tissue elements. It is commonly seen in crush injuries. The axon and its myelin sheath are broken, yet the surrounding connective tissue framework (i.e. the endoneurium, perineurium and epineurium) remain partially or fully intact [7].

Neurotmesis describes the most severe injury type, with disruption of the entire nerve and severe disruption of the connective tissue components of the nerve trunk with compromised sensory and functional recovery [7]. In neurotmesis, connective tissue framework is badly distorted or even lost [3]. Examples of neurotmesis are sharp injury, some traction injuries or injection of noxious drugs. Prognosis for spontaneous recovery is extremely suboptimal without surgical intervention [7].

Fig. 1 And cover figure sensory recovery after median axonotmesis. Redrawn from Seddon's original article [9]. Filled areas show anaesthetic areas. TD areas showing twopoint discrimination

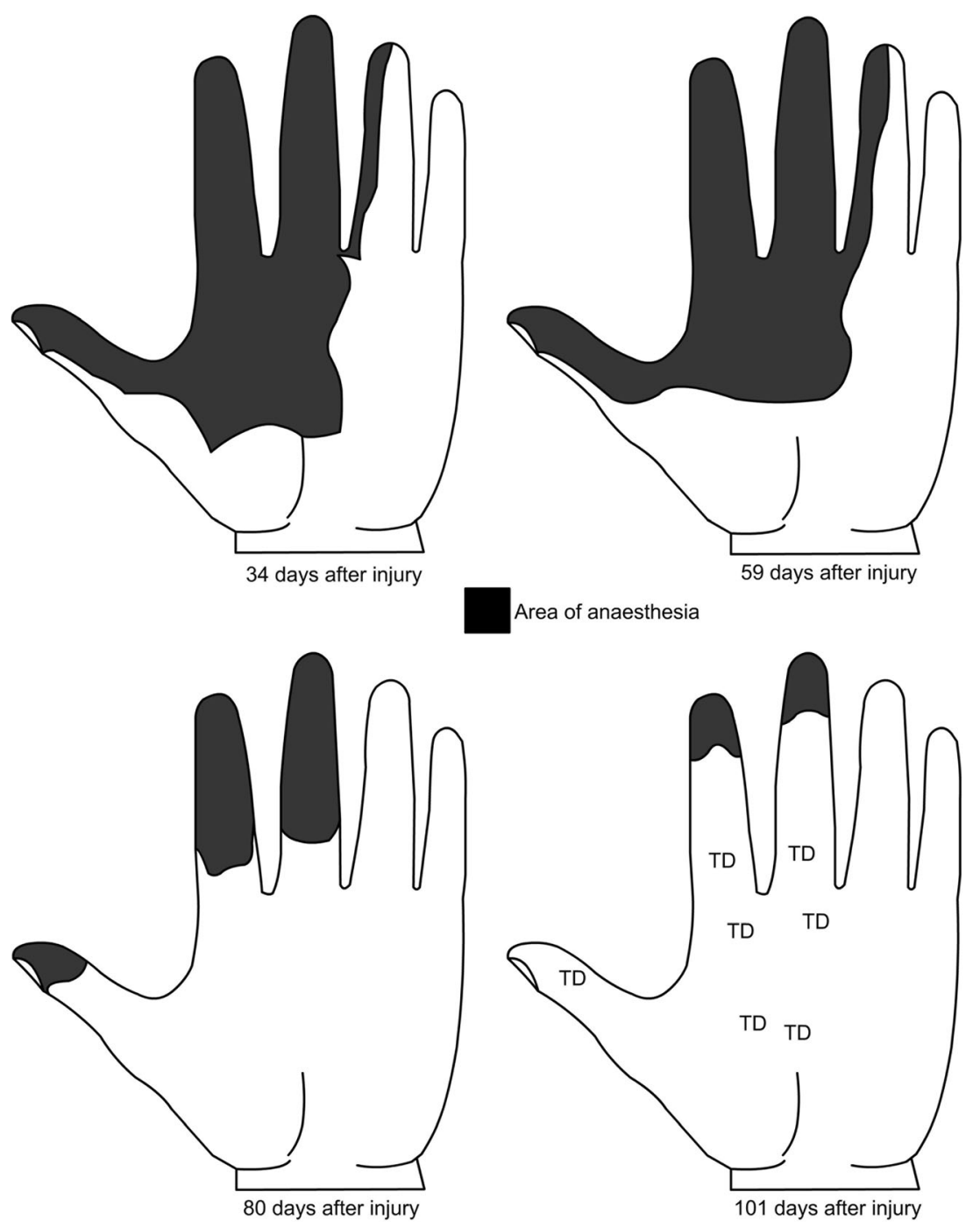



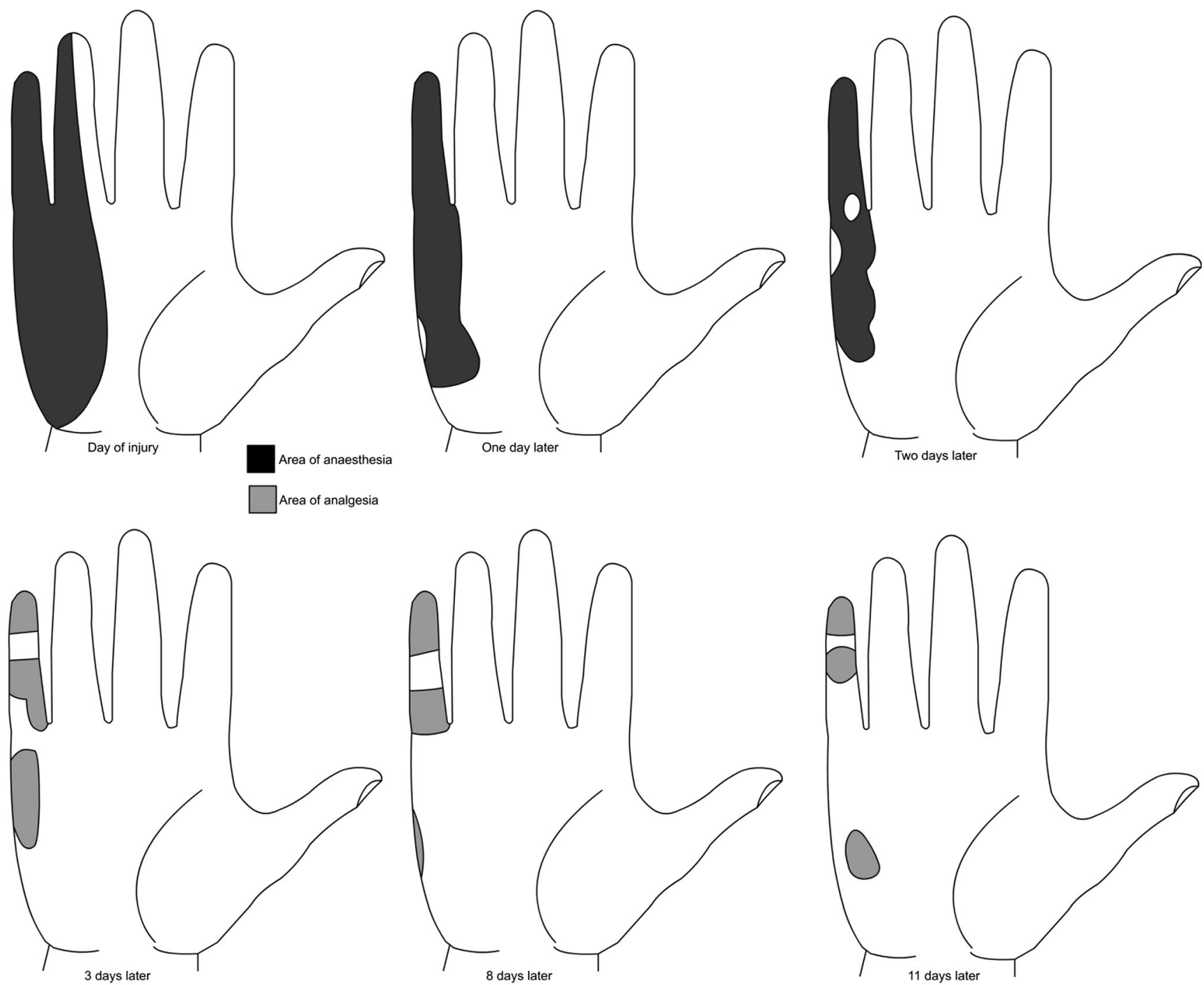

Fig. 2 Sensory changes after neurapraxia. Redrawn from Seddon's original article [9]. Filled areas show anaesthetic and analgesic areas.

Although the first classification scheme was introduced by Sir Herbert Seddon (1903-1977), the Sunderland classification scheme is more complex [3]. Sir Sydney Sunderland (1910-1993)[14] further stratified Seddon's three injury types into five categories according to severity of the injury. First degree injury is equivalent to Seddon's neurapraxia. Second, third and fourth degree injuries are equivalent to Seddon's axonotmesis, the difference being the degree of mesenchymal damage to the nerve. Fifth degree injury is equivalent to Seddon's neurotmesis [7].

\section{Conclusion}

Cut and crush injuries are doubtlessly the most frequently seen injuries since lacerations caused by sharp objects or long bone fractures are the most common types of the peripheral nerve trauma in peace and war time [5]. This is why world wars undoubtedly contributed more to our knowledge on peripheral nerve repair [2]. Traumatic peripheral nerve injuries are always a challenge to the clinician. However, first of all, the clinician needs to understand the anatomy of trauma (degree of trauma) since successful treatment requires a thorough knowledge of anatomy, pathophysiology of nerve injury and reconstructive options. In this respect, Seddon's classification based on his own personal and clinical observations during World War II and, of course, Sunderland's classification, help the clinician and neuroscientist for their further studies on management and treatment of peripheral nerve injuries.

Acknowledgments The authors thank the Akdeniz University Research Project Unit for their support.

Conflict of interest The authors declare no conflict of interest 


\section{References}

1. Bennett GJ, Xie YK (1988) A peripheral mononeuropathy in rat that produces disorders of pain sensation like those seen in man. Pain 33(1):87-107

2. Bristow WR (1947) Injuries of peripheral nerves in two world wars. Br J Surg 34(136):333-348

3. Campbell WW (2008) Evaluation and management of peripheral nerve injury. Clin Neurophysiol 119 (9):1951-1965. doi:10.1016/j. clinph.2008.03.018

4. Herbert John Seddon (1978) Lancet 1 (8054):54

5. Kaya Y, Sarikcioglu L (2014) Sciatic nerve injury models. Turkiye Klinikleri J Neurol-Special Topics (in press)

6. Maggi SP, Lowe JB 3rd, Mackinnon SE (2003) Pathophysiology of nerve injury. Clin Plast Surg 30(2):109-126
7. Robinson LR, Spencer Stelfa EL (2006) Diagnosis and rehabilitation of peripheral nerve injuries. In: Robinson LR (ed) Trauma rehabilitation. Lippincott Williams \& Wilkins, Philadelphia, pp 160-165

8. Rydevik B (1979) Compression injury of peripheral nerve. University Göteborg, Göteborg

9. Seddon HJ (1943) Three types of nerve injury. Brain 66 (4)

10. Seddon HJ (1954) Nerve grafting and other unusual forms of nerve repair. Spec Rep Ser Med Res Counc (G B) 282:389-417

11. Seddon HJ (1963) Nerve grafting. J Bone Joint Surg (Br) 45:447-461

12. Seddon HJ (1971) Surgical disorders of the peripheral nerves. Churchill Livingstone, Edinburgh

13. Sir Herbert Seddon, 1903-1977 (1978). J Bone Joint Surg Br 60-B (2):276-278

14. Sunderland S (1951) A classification of peripheral nerve injuries producing loss of function. Brain 74(4):491-516

15. Waldram M (2003) Peripheral nerve injuries. Trauma 5:79-96 